having lost some of their acquired immunity to malaria. This suggests that there may be some genetic advantage in this ethnic group. When chemoprophylaxis was taken the proportions with severe and mild malaria were almost equal in white people and Africans. Severe malaria was associated with a shorter duration of symptoms before presentation than mild malaria, suggesting that a severe attack of malaria may be essentially different from a mild attack and not merely a mild attack in which the symptoms have been neglected or ignored. This in turn may reflect different host-parasite interactions. It is of interest that surveys of fatalities have highlighted late diagnosis, as distinct from late presentation, as a major factor contributing to death. ${ }^{8}$

A greater proportion of patients taking chemoprophylaxis presented after a week or longer of symptoms, which could mean that their symptoms were initially milder. The highest proportion of severe to mild malaria was seen in southern and central and east Africa, but this was accounted for by the fact that this was the area predominantly visited by white people. Though severe malaria was relatively less commonly acquired in west Africa, this was due to the fact that most travellers to or from this region were Africans either visiting relatives in the United Kingdom or living in the United Kingdom and visiting relatives in west Africa. A greater proportion of women acquired severe malaria but women within the severe group had a lower uptake of chemoprophylaxis than men. Within the mild group there was no difference in the proportion of men and women taking chemoprophylaxis. A larger, prospective study would be needed to assess and confirm the results of our study.

Particularly worthy of further study are the risk of severe malaria in different endemic areas, the effects of full versus partial drug compliance, and a comparison of different prophylactic regimens.

The finding that in many cases apparent failure of chemoprophylaxis is, rather, a partial success should enhance the confidence which both doctors and travellers alike may place in antimalarial prophylaxis.

We thank the Public Health Laboratory Service Malaria Reference Laboratory at the London School of Hygiene and Tropical Medicine for assistance in providing patient data.

1 Lackritz EM, Lobel HO, Howell J, Boland P, Campbell CC. Imported Plasmodium falciparum malaria in American travellers to Africa. $\mathscr{f} A M A$ 1991;265:383-5.

2 Phillips-Howard PA, Radalowicz A, Mitchell J, Bradley DJ. Risk of malaria in British residents returning from malarious areas. $B M \mathcal{F}$ 1990;300:499-503.

3 Bradley DJ. Current trends in malaria in Britain. $\mathcal{F} R$ Soc Med 1989;82 (suppl 17): $8-13$.

4 Hall AP, Canfield CJ. Resistant falciparum malaria in Vietnam: its rarity in Negro soldiers. Proceedings of the Helminthological Society of Washington 1972;39:66-70

5 Westeyn JCFM, DeGeus A. Chloroquine resistant falciparum malaria imported into the Netherlands. Bull World Health Organ 1985;63:101-8.

6 Warrell DA, Molyneux ME, Beales PF, eds. Severe and complicated malaria. 2nd ed. World Health Organization division of control of tropical diseases. Trans $R$ Soc Trop Med Hyg 1990;84(suppl 2): 1-65.

7 Behrens RH, Pryce DI, Taylor RB, Low ST. Comparison of reported compliance to plasma levels of chemoprophylactic drugs in patients with malaria. In: Lobel HO, ed. Proceedings of 2 nd international conference on travel medicine, Atlanta, Georgia, 1991. In press.

8 Greenburg AE, Lobel HO. Mortality from Plasmodium falciparum malaria in travellers from the United States, 1959 to 1987. Ann Intern Med 1990;113: 326-7.

(Accepted 23 fuly 1992)

\title{
Cost of urology: financial audit in a clinical department
}

\section{Peter M Cuckow}

Abstract

Objectives - To cost a clinical unit over one month in 1991, to cost treatment of individual patients from audit data, and to compare this costing method with the hospital charging system.

Design-A financial breakdown was obtained for one month's work. Ward stay, operating time, investigations, and outpatient visits were costed and a formula (episode $=$ days on ward +hours of operating + investigations + outpatient visits) was used to cost patient episodes from audit data.

Setting-The adult urology unit in a teaching hospital.

Main outcome measures-Costs for each part of patients' treatment.

Results - Total cost was $£ 147796$ for 159 admissions, 738 inpatient days, 131 operations in 29 operating lists, and 615 outpatient visits. An uncomplicated transurethral prostatectomy cost $£ 1140$ but complications increased this to $£ 1500$ in another patient. The costs of diagnostic cystoscopy were $£ 130$ in outpatients, $£ 240$ in day surgery, and $£ 430$ in inpatients. Hospital charges do not reflect the individual costs of treatment, charges being greater than costs for some patients and lower than costs for others.

Conclusions-Clinicians can produce a financial analysis of their work and cost their patients' treatment. Audit is strongly advocated as a resource planning tool.

Department of Urology, Cambridge CB2 2QQ Peter $M$ Cuckow, research registrar

\section{Introduction}

Never have doctors needed greater financial insight. BMf 1992;305:743-6 service and change medical practice, although they are often inaccurate, not specific to an individual practice, and difficult to understand. I did a study to cost fully adult urology over one month at my hospital and answer the following questions: Can a clinician cost his or her unit? How much does the unit cost? How can this knowledge be applied? A costing formula was developed which allowed treatment of individual patients to be costed and provided further financial insights.

\section{Methods}

The study was conducted over 31 days (29 January to 28 February 1991) and a review of audit data showed that workload was comparable with that in previous months. The unit was divided into five areas to study use of resources: the ward, the operating theatre, the day surgery unit, outpatients, and investigations.

Most of the data required were already collected, manually or on computer, by the hospital so prospective data collection was unnecessary. Some laboratories with advanced costing systems could derive a bill for each consultant. For other areas Körner data, budgets, payroll information, and hospital price lists were used to derive costs.

Use of equipment and materials was determined from budget statements. Assessing each item separately, as done in my previous study, ${ }^{1}$ was considered too time consuming for the small costs incurred. More time was spent accounting for staff use. Staff costs were apportioned according to the amount of time spent working in the unit. Workload and patient information were available from computerised audit and the hospital's case mix system. 
The medical team comprised two consultants, four junior staff, two clinical assistants, and two secretaries. The total salary cost was $£ 19130$ for the month, each salary was then apportioned to the five clinical areas by time spent. Pay for on call work was assigned to inpatient costs and secretarial costs to outpatients, where the secretaries worked exclusively. Thus separate medical staff costs were obtained for each clinical area. Overheads were included in each clinical area to account for shared services, as were capital charges (table I).

TABLE I-Calculation and allocation of overheads in urology unit

\begin{tabular}{|c|c|}
\hline Overhead (clinical area applied) & Method of calculation \\
\hline $\begin{array}{l}\text { Domestic, energy, grounds and } \\
\text { gardens, engineering, building } \\
\text { estates (all areas) }\end{array}$ & Per area or volume of service area \\
\hline Central administration (all areas) & $£ 0.04$ per $£ 1.00$ spent \\
\hline $\begin{array}{l}\text { Medical records, portering (ward } \\
\text { and outpatients) }\end{array}$ & $\begin{array}{l}\text { Per patient activity (inpatient days } \\
\text { and outpatient visits) }\end{array}$ \\
\hline Capital charge (all areas) & $19 \cdot 61 \%$ surcharge \\
\hline
\end{tabular}

TABLE II -Breakdown of one month's ward costs

\begin{tabular}{lr}
\hline & Cost $(£)$ \\
\hline Nursing & 14900 \\
Medical staff & 7805 \\
Food and catering & 4600 \\
Ward administration & 2280 \\
Pharmacy & 2000 \\
Cleaning & 1890 \\
Laundry and linen & 1730 \\
Intensive therapy or high dependency unit & 1430 \\
Medical and surgical supplies & 980 \\
Physiotherapy & 250 \\
Overheads & 10860 \\
Capital charge & 9555 \\
\hline Total & 58280 \\
\hline
\end{tabular}

TABLE III - Breakdown of one month's surgical costs

\begin{tabular}{lcc}
\hline & $\begin{array}{c}\text { Main theatres } \\
(\mathfrak{})\end{array}$ & $\begin{array}{c}\text { Day surgery } \\
(£)\end{array}$ \\
\hline Nursing & 7210 & 696 \\
Anaesthetists & 6590 & 416 \\
Medical staff & 4763 & 689 \\
Operating assistant/officer & 3120 & 293 \\
Pharmacy & 2580 & 154 \\
Medical or surgical supplies & 1550 & 49 \\
Cleaning & 200 & 64 \\
Miscellaneous & 830 & 23 \\
Prostheses & 2190 & 250 \\
Overheads & 2550 & 517 \\
Capital charge & 6193 & 3151 \\
\hline Total & 37776 & \\
\hline
\end{tabular}

Individual patient episodes were divided into four components: patient episode $=$ days on the ward + hours of operating time+outpatient visits +investigations performed. This basic information on patients was collected routinely for audit, and unit costs were derived for each component. A day on the ward and an outpatient visit were costed by dividing ward and outpatient costs by the number of inpatient days and outpatient visits respectively. Theatre time (from the start of anaesthesia to the end of the procedure) was costed from theatre and day surgery costs and the time used in each. Each investigation was also priced.

The formula was then used to study the unit's practice. Initially, the cost of treating selected patients was estimated, including some patients with surgical complications to show the extra costs. Secondly, the relative costs of procedures done in outpatients, day surgery, and main theatres were studied. Finally, the hospital's own patient costing technique, which is used to derive charges for purchasers, was compared with the costing formula.

\section{Results}

The total cost for the month was $£ 147796$. The ward costs for 159 patients staying 738 inpatient days, were $£ 58280$ (table II). Table III shows the costs of main theatres (£37 776 for 26 lists, 104 operations and 77 hours 23 minutes operating) and day surgery ( $\$ 3151$ for three lists, 27 operations and 8 hours 38 minutes operating). The 615 outpatient visits (with 54 procedures and 10 cystometrograms) cost $£ 17933$ (table IV). Investigations cost $£ 30656$ (table V) and included 1087 blood tests, 430 radiographs, 28 isotope studies, and 60 histology specimens.

The above data were used to derive unit costs for each component of treatment. Costs were $£ 78.97 /$ day for ward stays, $£ 488.19 /$ hour for theatre time, $£ 362.80$ /hour for day surgery time, and $£ 29.16 /$ visit for outpatient visits; investigations were costed according to the hospital's price list. Table VI shows the application of the costing formula for selected patients. Table VII shows the differences in costs entailed when performing procedures as inpatient, day surgery, or outpatient cases.

Addenbrooke's charges $£ 190$ per day and $£ 45$ per outpatient visit for urology, based on averages designed to recoup expenditure. These charges were assessed for several patient episodes to see if this aim was fulfilled (table VIII). Large discrepancies in three of the five patients showed charges do not reflect individual costs. Twenty five consecutive inpatient stays were then costed by both techniques and charges were $11 \%$ more than costs (table IX). Within this group one patient requiring little more than bed rest (renal colic) and another having major surgery (cystectomy) produced charges $65 \%$ above and $28 \%$ below cost.

\section{Discussion}

The white paper Working for Patients ${ }^{2}$ developed Griffiths's philosophy that hospital departments should be financially accountable ${ }^{3}$ and introduced resource management to increase efficiency through better information. Hospitals have divided into budget holding departments, and better information is now available. Unfortunately, clinicians work in many different departments and cannot get a full picture of their costs. Management averages or best guesses do not reflect individual practice or give complete costing of a clinical unit.

The total cost of the adult urology service (£147 796) was almost 3\% of Addenbrooke's monthly budget. Salaries formed the largest part of the costs $56 \%$ in wards and outpatients and $70 \%$ and $82 \%$ in theatres and day surgery), emphasising the importance of accounting for staff use. Medical and surgical supplies accounted for only $2 \%$ of ward costs and $4.9 \%$ of theatre costs, so the decision not to itemise them was vindicated. Expensive items included one night on intensive care and two on the high dependency unit at $2.5 \%$ of ward costs and two prostheses (one penile and one testicular), contributing $6.9 \%$ of main theatre costs. Pharmacy was only $4 \cdot 1 \%$ of the ward costs, and in theatres, where it included all anaesthetic drugs, intravenous fluids, and lotions, pharmacy was only $8.2 \%$ of the cost. Costs were similarly distributed in

TABLE V -Costs of investigations for urology for one month $(£)$

\begin{tabular}{lrrr}
\hline & Cost & Capital charge & Total cost \\
\hline Radiology & 12610 & 2473 & 15083 \\
Blood bank & 5740 & 1125 & 6865 \\
Nuclear medicine & 2410 & 472 & 2882 \\
Microbiology & 1760 & 345 & 2105 \\
Histopathology & 1090 & 214 & 1304 \\
Biochemistry & 820 & 161 & 981 \\
Haematology & 810 & 159 & 969 \\
Electrocardiography & 390 & 76 & 466 \\
\hline
\end{tabular}




\begin{tabular}{|c|c|c|c|c|c|c|}
\hline Patient details & Complications & $\begin{array}{l}\text { Ward stay } \\
\text { (No of days) }\end{array}$ & $\begin{array}{l}\text { Operating time } \\
\text { (mins) }\end{array}$ & $\begin{array}{l}\text { Outpatients } \\
\text { (No of visits) }\end{array}$ & Investigations & $\begin{array}{l}\text { Total } \\
\text { cost }\end{array}$ \\
\hline $\begin{array}{l}\text { Circumcision in man aged } 63 \\
\text { Nephrectomy in woman aged } 44\end{array}$ & None & $157.94(2)$ & $244.10(30)$ & $58.32(2)$ & 28.14 & 488.50 \\
\hline $\begin{array}{l}\text { (pyelonephritis) } \\
\text { Cystoscopy in man aged } 48 \text { (urinary }\end{array}$ & None & $473.82(6)$ & $870.61(107)$ & $58.32(2)$ & 262.89 & 1665.64 \\
\hline $\begin{array}{l}\text { frequency) } \\
\text { Transurethral prostatic resection in }\end{array}$ & None & $157.94(2)$ & $146.46(18)$ & $87.48(3)$ & 42.11 & 433.99 \\
\hline $\begin{array}{l}\text { man aged } 77 \text { (prostatism) } \\
\text { Cystoscopy in man aged } 52\end{array}$ & None & $394.85(5)$ & $504.46(62)$ & $87.48(3)$ & 155.45 & 1142.24 \\
\hline (haematuria) & Postoperative fever & $315.88(4)$ & $130.18(16)$ & $87.48(3)$ & 71.26 & 604.80 \\
\hline $\begin{array}{l}\text { Transurethral prostatic resection in } \\
\text { man aged } 80 \text { (prostatism) }\end{array}$ & $\begin{array}{l}\text { Postoperative bleeding, clot retention, } \\
\text { and septicaemia }\end{array}$ & $631.76(8)$ & $447.51(55)$ & $87.48(3)$ & 340.39 & 1506.75 \\
\hline
\end{tabular}

TABLE VII - Cost (£) of treatment done in inpatients, day surgery, and outpatients

\begin{tabular}{lccc}
\hline & Inpatient & Day surgery & Outpatients \\
\hline Cystoscopy & 433.99 & 238.43 & 129.59 \\
Circumcision & 488.50 & 267.86 & 74.78 \\
Vasectomy & & 196.79 & \\
\hline
\end{tabular}

TABLE VIII - Comparison of cost of treatment derived from audit with hospital charges

\begin{tabular}{lcc}
\hline & $\begin{array}{c}\text { Cost derived } \\
\text { from audit } \\
\text { method } \\
(£)\end{array}$ & $\begin{array}{c}\text { Hospital charge for } \\
\text { procedure }(1991 \\
\text { rates: £190/day and } \\
£ 45 \text { per visit) } \\
(£)\end{array}$ \\
\hline Cystoscopy & 433.99 & 515 \\
Transurethral prostatic resection & 1142.24 & 1085 \\
Circumcision & 488.50 & 470 \\
Nephrectomy & 1665.64 & 1275 \\
Vasectomy (outpatient) & 74.78 & 90
\end{tabular}

TABLE IX-Differences between audited inpatient costs and hospital charges (£s)

\begin{tabular}{lcrrr}
\hline & $\begin{array}{c}\text { Costs derived } \\
\text { from audit } \\
\text { method }\end{array}$ & $\begin{array}{c}\text { Hospital } \\
\text { charges } \\
(£ 190 / \text { day })\end{array}$ & $\begin{array}{c}\text { Difference } \\
(\%)\end{array}$ \\
\hline 25 Consecutive patients (101 & & & & \\
$\begin{array}{l}\text { patient days) } \\
\text { Renal colic (5 days) }\end{array}$ & 17283 & 19190 & 1907 & $(11)$ \\
Cystectomy (11 days) & 346 & 570 & 224 & $(64 \cdot 7)$ \\
& 2889.22 & 2090 & $799.22(27 \cdot 7)$ \\
\hline
\end{tabular}

main theatres and day surgery, where all three lists had anaesthetic cover. The large size of outpatients and its high patient turnover account for its high overheads (29.5\%).

Radiology and nuclear medicine formed the bulk of the investigations. The high blood bank costs reflect a policy of crossmatching blood for all patients having prostatectomy. The other costs mainly arose from routine and preoperative and postoperative tests.

In 1989 the NHS Management Executive suggested that all direct costs needed to be identified and all indirect costs allocated to individual patients. ${ }^{4} \mathrm{My}$ simple costing formula achieves this. Episodes were divided into components for which data are routinely collected for audit, enabling rapid financial assessment once core costs are known. Finance managers are often criticised for considering cost alone and neglecting quality of patient care, while surgeons assess quality with audit but cannot relate it to cost. This system combines cost and outcome, the two essential elements required to assess efficiency. ${ }^{5}$

\section{COST AND QUALITY CARE}

Performing procedures in outpatients or day surgery rather than main theatres reduced costs considerably (table VII). The Audit Commission suggested that operating more in day surgery and outpatients saves resources, ${ }^{6}$ and up to $50 \%$ of all operations could be day cases. ${ }^{7}$ But savings can result only when freed inpatient capacity is closed or transferred to another specialty ${ }^{8}$ as its continued use will increase workload and expenditure. Surgeons, concerned more with expanding their practice than reducing its costs, fear bed and list closures but might agree if savings were reinvested in other areas of their work.

Previously published figures for surgical ward costs vary from $£ 75^{9}$ to $£ 110^{10}$ and $£ 149.93^{11}$ per day. All are based on averages and exclude theatre costs, although few details of their derivation were given. The Bevan report ${ }^{12}$ costed inpatient and outpatient operating time and has been used in discussions of theatre use. ${ }^{911}$ Corrected for 1990-1 prices, costs for inpatient and outpatient operating time are $£ 183.87 /$ hour and $£ 137.70$ /hour. ${ }^{11}$ These data from 1987, may not adequately assess staff costs and overheads and omit capital charges. In my study the 26 operating sessions were costed and hourly operating costs calculated by using the 77 hours 23 minutes that had been used, rather than the 91 hours available. This gives a higher hourly cost but reflects efficiency in theatre and prevents unfilled time from being lost. Although day surgery sessions included anaesthesia, ratios of inpatient to day surgery theatre costs are similar to those in other studies. Different methods of allocating overheads and medical staff, the inclusion of capital charges, specialty differences, and inflation account for discrepancies between these results and those of my study in 1989.1

Taking individual elements of the cost out of context can be misleading. Filer et al looked at use of disposables in cataract surgery and suggested a saving of $£ 22000$ a year was possible if all eight consultants in their department changed to less expensive materials. ${ }^{13}$ Though commendable, this saving would represent a fraction of the cost of such a department. If, alternatively, more expensive equipment enables a quicker operation or a shorter hospital stay, or both, greater savings could be made.

\section{VALUE OF AUDIT}

Audit is now part of every surgeon's practice and its potential as a resource planning tool should not be underestimated. I have found it a more reliable and accessible source of patient information than the hospital case mix system. By combining audit information with core financial data a patient costing system can be developed, based on a simple formula which is easy to understand and operate. This formula provides clinicians with valuable and hitherto elusive information that is specific for both the patient and the consultant. Cost saving measures can be directed either at decreasing ward stay, theatre time, outpatient visits, and investigations (changing practice) or at lowering their unit costs (increasing efficiency).

I thank Messrs P T Doyle and K N Bullock for encouraging this study of their unit and Ms S Stanway of Addenbrooke's Unit finance department for her help and guidance.

1 Cuckow PM. Cost can and must be a part of surgical audit. Ann R Coll Surg Eng (in press). 
2 Secretaries of State for Health, Wales, Northern Ireland, and Scotland. Working for patients. London: HMSO, 1989.

3 NHS Management Enquiry. Report. London: DHSS, 1983. (Griffiths report) 4 NHS Management Executive. Resource management initiative information package-acute hospitals. London: HMSO, 1989.

5 Hall J, Mooney G. What every doctor should know about economics. 1. The benefits of costing. Med f Aust 1990;152:29-31.

6 Audit Commission for Local Authorities and the National Health Service. A short cut to better services: day surgery in England and Wales. London HMSO, 1990

7 Burn JMB. Responsible use of resources: day surgery. BMF 1983;286:492-3.

8 Berry MG, Briggs TP, Parker C, Miller RA. Beds or day case unit: your choice? Ann R Coll Surg Eng 1991;73(suppl):114-6.
9 Opit LJ, Collins REC, Campbell G. Use of operating theatres: the effects of case mix and training in general surgery. Ann R Coll Surg Eng 1991;73: 389.93

10 Ellis BW. Rivett RC, Dudley HAF. Extending the use of clinical audit data: a resource planning model. BMf 1990;301:159-62.

11 NHS Management Executive Value for Money Unit. Day surgery, making it happen. London: HMSO, 1991.

12 NHS Management Executive. The management and utilisation of operating departments. London: HMSO, 1989.

13 Filer J, Roberts-Harry TJ, Jagger JD. Cutting the cost of cataract surgery-a financial audit. Br f Ophthalmol 1991;75:227-8.

(Accepted 30 fuly 1992)

\title{
Outcome of breech delivery at term
}

\author{
J G Thorpe-Beeston, P J Banfield, N J StG Saunders
}

Department of Obstetrics, St Mary's Hospital, Praed Street, London W2 1PG J G Thorpe-Beeston, registrar

P J Banfield, research registrar N J StG Saunders, senior lecturer

Correspondence to: Dr N J StG Saunders, Princess Anne Hospital, Southampton SO9 4HA.

\section{Abstract}

Objective-To compare neonatal mortality and morbidity in term infants presenting by the breech and delivered vaginally or by caesarean section.

Design-Population based comparison of outcomes. Data derived from the St Mary's maternity information system.

Setting-North West Thames Regional Health Authority, 1988-90.

Subjects -3447 singleton fetuses presenting by the breech at term.

Main outcome measures - Intrapartum and neonatal mortality, low Apgar scores, intubation at birth, and admission to special care baby units.

Results-After the exclusion of babies with congenital anomalies the incidence of intrapartum and neonatal death associated with vaginal birth was $8 / 961(0.83 \%)$ compared with $1 / 2486(0.03 \%)$ in babies born by caesarean section (relative risk 20, $95 \%$ confidence interval 2.5 to 163 ). The numbers of low Apgar scores and neonatal intubation were doubled in babies born vaginally or by emergency caesarean section compared with those delivered by elective operation.

Conclusions-The good neonatal outcome associated with elective caesarean delivery of the term breech fetus may influence the decision of women and their obstetricians about mode of delivery.

\section{Introduction}

The optimal management of breech presentation at term remains a lively debating issue in graduate examinations, on the labour ward, and in the obstetric literature. The opinions of many have been polarised by their personal experiences, good and bad, and there have been no prospective randomised trials of sufficient size to resolve this issue. In the absence of such information, obstetricians have to rely on data derived from retrospective analysis. We examined the neonatal mortality and early morbidity associated with vaginal delivery of breech fetuses at term in one health region over three years and compared the outcome with those cases managed by caesarean section.

\section{Patients and methods}

The St Mary's maternity information system is an on line collection system for obstetric data currently in use in all maternity units within the North West Thames Health region. Data are collected prospectively from booking until 28 days after delivery. At the end of each year patient identifiers are removed and the total data set is pooled for analysis. The data for this study were derived from 117000 consecutive deliveries occurring between January 1988 and December 1990. The present analysis was confined to those pregnancies in which a singleton fetus in a breech presentation was delivered after 37 completed weeks of pregnancy. Studied outcome measures included intrapartum stillbirth, neonatal death, low $(<7)$ Apgar scores at 5 minutes, the need for neonatal ventilation, and admission to special care baby units. Relative risks were calculated with CIA software.

\section{Results}

A total of 3447 women delivered mature singleton infants presenting by the breech. This represented nearly $3 \%$ of the total births in the study period. Of these, 1457 (42\%) were delivered by elective caesarean section before the onset of labour, $1029(30 \%)$ by emergency caesarean section in labour, and $961(28 \%)$ vaginally. After we excluded antepartum stillbirths (11) and deaths associated with congenital anomalies (4) there were four intrapartum and four neonatal deaths in the group managed by vaginal delivery, an incidence of $0.83 \%$. In the 2486 cases delivered by caesarean section there was only one neonatal death of a normally formed infant, an incidence of $0.03 \%$ (relative risk $20,95 \%$ confidence interval 2.5 to 163 ), and three further perinatal deaths associated with congenital abnormality. In the same period, after antepartum stillbirths and those fetuses with congenital abnormalities were excluded, there were 77 intrapartum and neonatal deaths of mature singleton fetuses presenting cephalically and delivered vaginally, an incidence of $0.08 \%$ ( 77 of 93602 ).

The mean birth weights of the breech fetuses delivered vaginally, by emergency caesarean section, and by elective caesarean section were $3169 \mathrm{~g}, 3294 \mathrm{~g}$, and $3290 \mathrm{~g}$ respectively. The table gives details of Apgar scores, resuscitations, and admissions to the special care baby units.

\section{Discussion}

Ways of managing breech presentations at term include attempted external cephalic version, planned caesarean section, and trial of vaginal delivery. Although many authors now recommend a trial of vaginal delivery, individual series do not contain sufficient numbers of patients to gain a true estimate of the neonatal risks. ${ }^{24}$ By pooling data from recent publications Bingham and Lilford calculated that the excess risk of neonatal death attributable to vaginal delivery of the term breech was about 4 per $1000 .^{5}$ The same figure was reached after analyses of two large obstetric databases ${ }^{67}$ and agrees with our own findings. These database studies, however, excluded stillbirths and so may have underestimated the risks of vaginal breech delivery. Our data suggest that the total risk of intrapartum and neonatal loss in normally formed 